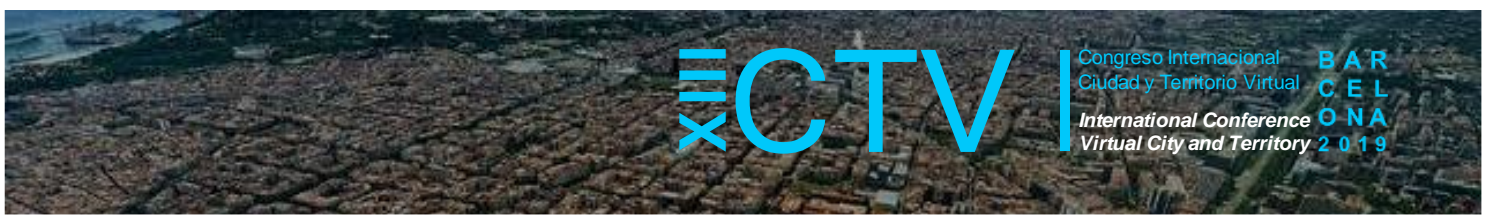

\title{
AMÓN_RA: LA UTILIZACIÓN DE TIC PARA REVALORIZAR Y DINAMIZAR UN BARRIO HISTÓRICO DE COSTA RICA
}

\author{
Porras-Alfaro, David ${ }^{1 *}$; García-Baltodano, Kenia ${ }^{2}$ \\ Remisión inicial: 2019-05-29; Remisión definitiva: 2019-2010; Publicación: 2019-12-21
}

Citación: Porras-Alfaro, D. y García-Baltodano, K. (2019). Amón_RA: la utilización de TIC para revalorizar y dinamizar un barrio histórico de Costa Rica. En XIII CTV 2019 Proceedings: XIII International Conference on Virtual City and Territory: "Challenges and paradigms of the contemporary city": UPC, Barcelona, October 2-4, 2019. Barcelona: CPSV, 2019, p. 8448. E-ISSN 2604-6512. DOI http://dx.doi.org/10.5821/ctv.8448

\section{Resumen}

El proyecto de investigación Amón_RA está desarrollando tecnología de realidad aumentada para la puesta en valor y difusión del paisaje urbano histórico (PUH) de barrio Amón; la cual se pretende mostrar a través de una aplicación móvil y una página WEB. Esta aportación tiene por objetivo evidenciar los recursos que han sido identificados a partir del proyecto y analizados desde dos perspectivas, una, centrada en la revalorización de este espacio como PUH y otra, enfocada en las oportunidades de dinamización económica y social.

La ponencia, se construye a partir de los resultados obtenidos en un proceso iniciado en 2017, por el proyecto de investigación 'Amón_RA. Implementación de la realidad aumentada como herramienta para la puesta en valor y difusión del paisaje urbano histórico de barrio Amón', desarrollado por las Escuelas de Arquitectura y Urbanismo, Diseño Industrial y Computación del Instituto Tecnológico de Costa Rica, con la participación del Departamento de Geografía de la Universidad Autónoma de Madrid, la Municipalidad de San José y el Centro de Investigación y Conservación del Patrimonio Cultural del Ministerio de Cultura y Juventud.

Metodológicamente, la identificación de recursos se realizó mediante el levantamiento de información en sitio. Posteriormente, se realizaron procesos participativos para contrastar y complementar la información obtenida con la visión de los agentes sociales del barrio. Seguidamente, se procedió a la clasificación de los recursos, en paralelo a la generación de contenidos para las TIC. Con dichos resultados, se evidencian los recursos con valores patrimoniales y aquellos con potencial de dinamización socio-cultural, económica y ambiental. Entre los datos utilizados destacan la información cuantitativa obtenida de los levantamientos en campo, la información cualitativa producto de los procesos participativos; además de una revisión detallada de fuentes bibliográficas y documentales.

El proyecto Amón_RA, siguiendo los planteamientos de UNESCO (2011) apela al uso de TIC como herramienta que contribuya a la educación y la sensibilización en cuanto al patrimonio cultural, al facilitar información que permita ampliar los contenidos históricos, culturales, urbanos y patrimoniales. A la vez, se pretende que sirva como instrumento para dar a conocer recursos y actividades ofertadas con la intención de promover la dinamización económica y social de este sector de la ciudad josefina.

Entre los resultados obtenidos se encuentra la geolocalización de los recursos tangibles. Dentro de los recursos con valores patrimoniales se lograron ubicar 23 edificaciones de interés arquitectónico, nueve de las cuales cuentan con declaratoria de Patrimonio Histórico-Arquitectónico; además, se logró identificar siete espacios a los que se les denominó 'Pasado perdido', los que responden a edificaciones desaparecidas pero que aún se mantienen en la memoria colectiva, al igual que 19 espacios en los cuales se establecieron 'Secretos', entendidos como aspectos poco conocidos de los inmuebles pero interesantes de difundir. Finalmente, dentro de esta categoría, se localizaron tres elementos naturales de importancia para el barrio.

Como recursos con potencial de dinamización, se encontraron una serie de elementos que conforman la 'Oferta Urbana' del barrio, la cual está compuesta por 14 locales gastronómicos, 12 equipamientos ligados a la cultura y arte, 8 sitios de hospedaje y 12 instituciones públicas. Todos estos resultados se han traducido a contenidos dentro de la aplicación móvil y página WEB, los cuales pueden ser visualizados a través de recursos como mapas interactivos, fotografías, realidad aumentada, modelos $3 \mathrm{D}$ y fotografías $360^{\circ}$.

Los recursos intangibles se han clasificado en información sobre los orígenes del barrio, vivencias, personajes y actividades del barrio. Esta información se visualiza en una línea del tiempo interactiva, así como en contenido textual e ilustrativo vinculado a los recursos tangibles.

\footnotetext{
${ }^{1}$ Arquitecto, Dr. Escuela de Arquitectura y Urbanismo, Instituto Tecnológico de Costa Rica, https://orcid.org/0000-00028917-1652 y ${ }^{2}$ Arquitecta, Dra. Escuela de Arquitectura y Urbanismo, Instituto Tecnológico de Costa Rica, https://orcid.org/0000-0002-2507-8627. * Correo de contacto: dporras@tec.ac.cr
} 


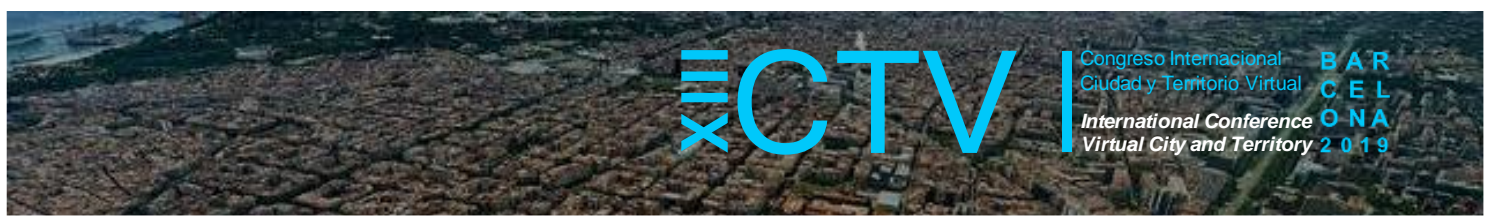

Como principal conclusión, se evidencia que, a pesar de su despoblamiento y terciarización, Amón es un barrio josefino que cuenta con una serie de valores patrimoniales de tipo histórico, estético, simbólico, cultural y social que lo convierten en un referente de la ciudad y de los diversos procesos que han moldeado su configuración urbana. Además, cuenta con una serie de recursos y servicios con potencial para dinamizar el barrio a través de las TIC.

\section{Abstract}

The Amón RA research project is developing augmented reality technology for the enhancement and dissemination of the historic urban landscape (HUL) of barrio Amón; which is intended to show through a mobile application and a web page. This contribution aims to demonstrate the resources that have been identified from the project and analyzed from two perspectives, one, focused on the revaluation of this space as HUL and another, center around the opportunities for economic and social revitalization.

The paper considers part of the results obtained in a process initiated in 2017, by the research project 'Amón_RA. Implementation of augmented reality as a tool for the enhancement and dissemination of the historic urban landscape of barrio Amón', developed by the Schools of Architecture and Urbanism, Industrial Design and Computing of the Instituto Tecnológico de Costa Rica, with the participation of the Department of Geography of the Universidad Autónoma de Madrid, the Municipality of San José and the Center for Research and Conservation of Cultural Heritage of the Ministry of Culture and Youth.

Methodologically, the identification of resources was carried out by collecting information on site. Subsequently, participatory processes were carried out to contrast and complement the information obtained with the vision of the social agents of the neighborhood. Next, the resources were classified, in parallel to the generation of ICT content. With these results, resources with patrimonial values are evidenced and those with potential for socio-cultural, economic and environmental dynamization. Among the data used, the quantitative information obtained from the field surveys and the qualitative information produced by the participatory processes stand out; in addition to a detailed review of bibliographic and documentary sources.

The Amón_RA project, following the approaches of UNESCO (2011), appeals to the use of ICT as a tool that contributes to the education and awareness of cultural heritage, by providing information that allows to expand the historical, cultural, urban and heritage contents. At the same time, it is intended to serve as an instrument to publicize resources and activities offered with the intention to promote the economic and social revitalization of this sector of San José.

Among the results obtained is the geolocation of tangible resources. Within the resources with heritage values, 23 buildings of architectural interest were found, nine of which have a declaration of Historical-Architectural Heritage; in addition, it was possible to identify seven spaces that were called 'Lost Past', those that respond to missing buildings but remain in the collective memory, as well as 19 spaces in which 'Secrets' were established, understood as little known aspects of real estate but interesting to spread. Finally, within this category, three natural elements of importance to the neighborhood were located.

As resources with dynamism potential, a series of elements that make up the 'Urban Offer' of the neighborhood were found, which is composed of 14 gastronomic venues, 12 facilities linked to culture and art, 8 lodging services and 12 public institutions. All these results have been translated into the content of the mobile application and web page, which can be visualized through resources such as interactive maps, photographs, augmented reality, 3D models and $360^{\circ}$ photographs.

Intangible resources have been classified into information about the origins of the neighborhood, experiences, characters, and activities of the neighborhood. This information is visualized in an interactive timeline, as well as in textual and illustrative content linked to tangible resources.

The main conclusion, it is evident that, despite its depopulation and outsourcing, Amón is a neighborhood in San José that has a series of historical, aesthetic, symbolic, cultural and social heritage values that make it a reference in the city and of the various processes that have shaped its urban configuration. Besides, it has a series of resources and services with the potential to stimulate the neighborhood through ICT.

Palabras Clave: Barrio Amón; Paisaje Urbano Histórico; puesta en valor del patrimonio; aplicación móvil y web

Key words: Barrio Amón; Historic Urban Landscape; cultural heritage valorization; mobile app and website

\section{Las TIC y el paisaje urbano histórico}

Las nuevas tecnologías de la información y la comunicación (TIC) constituyen herramientas que han revolucionado la forma de interactuar y entender el entorno a partir de las posibilidades que brindan a los usuarios al contar con un mayor acceso a la información. Si 


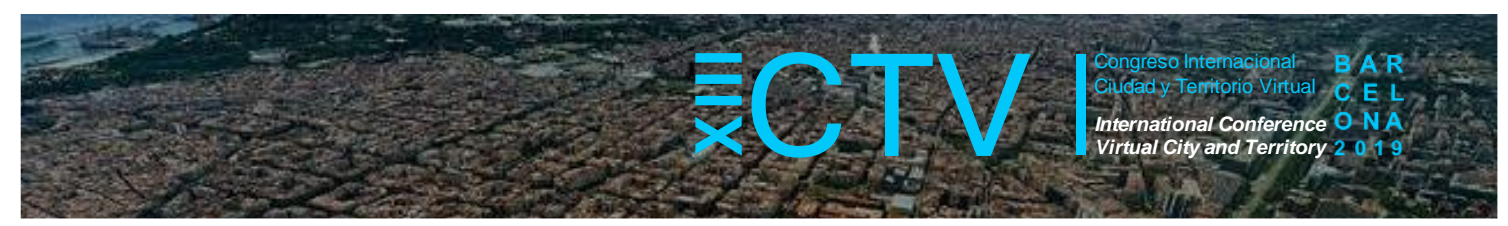

bien existen diversas discusiones respecto al uso de la TIC y sus posibles efectos, tanto positivos como negativos (Barrado-Timón \& Hidalgo-Giralt, 2019), lo cierto es que son herramientas de gran uso en la actualidad y que ofrecen una serie de beneficios en temáticas como la organización del tránsito, el medio ambiente, la seguridad de espacios públicos, el planeamiento urbanístico, el transporte público, el turismo, la cultura, entre otros.

Ante el constante crecimiento de las áreas urbanas y la presencia de problemáticas como el despoblamiento, la terciarización y el abandono en los centros urbanos, que afectan la memoria histórica, los valores patrimoniales y la posibilidad de articular nuevas actividades productivas en dichas zonas, las TIC se convierten en un aliado estratégico como herramienta de dinamización y gestión.

A nivel internacional, los Objetivos de Desarrollo Sostenible (Naciones Unidas, 2016) promueven el acceso a las nuevas tecnologías de información y comunicación; situación que defienden los planteamientos emanados de la Nueva Agenda Urbana (Naciones Unidas, 2017) con una visión de integración territorial por medio de la conectividad de espacios, el desarrollo de TIC y estrategias de gobierno electrónico. Acorde a estas ideas, la Recomendación de UNESCO sobre el Paisaje Urbano Histórico (UNESCO, 2011) alienta el uso de TIC para registrar, entender y exponer estos complejos espacios urbanos.

El concepto de Paisaje Urbano Histórico (PUH) plantea que la ciudad es un continuo espacial y temporal, en el que se suma el legado de incontables grupos de población (UNESCO, 2013). Por ende, para lograr la conservación de estos espacios se requiere analizar los diferentes puntos de vista de los agentes que participan en su construcción social que, como menciona Taylor (2016), contribuye a comprender los diversos significados que las personas atribuyen a los paisajes urbanos. Como señalan Ginzarly et al. (2018) el PUH no es una nueva categoría de patrimonio sino una herramienta que integra políticas y prácticas de conservación, en busca de lograr un desarrollo más holístico basado en los valores del patrimonio urbano.

\subsection{Ampliando la realidad a través de las TIC}

La Realidad Aumentada (RA) constituye una herramienta innovadora y atractiva. Su uso a nivel internacional está ampliamente difundido; sin embargo, en Costa Rica su utilización está en una etapa inicial, sobre todo cuando su finalidad es estar al servicio del patrimonio y el PUH de una ciudad. Esta tecnología permite visualizar el mundo real a través de un dispositivo móvil, incorporando información textual y multimedia que enriquece la realidad de un usuario a través de medios virtuales. Con ella, se pretende acercar a las personas a una vivencia más interactiva de la ciudad, con fines educativos, culturales y turísticos vinculados al desarrollo local.

La realidad aumentada consiste en la combinación de información digital en tiempo real con el campo de visión de un usuario (Johnson et al., 2013) haciendo que la persona pueda percibir los objetos virtuales como parte del mundo real (Azuma, 1997). Como señala Fombona et al. (2012) esta tecnología relaciona imágenes, posición geográfica y metadatos asociados en un equipo informático; esto permite al usuario ampliar su experiencia más allá del contacto con los objetos y el entorno físico. 


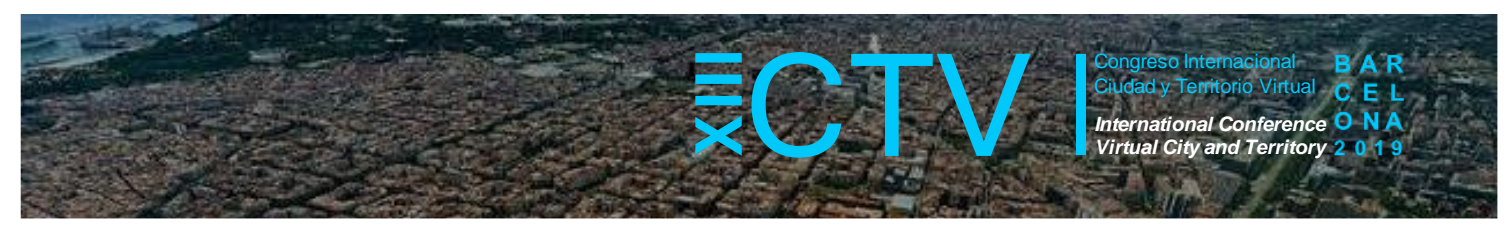

Autores como Blanco-Pons et al. (2019), Syahputra et al. (2019) y Palma et al. (2019) señalan la utilidad de este tipo de tecnología al servicio de la puesta en valor del patrimonio cultural, tanto en lo que respecta a su conservación como a su dinamización a través del turismo. Museos, sitios arqueológicos y ciudades históricas son algunos de los espacios en los cuales se ha utilizado la RA para brindar mayor información a los usuarios, por ejemplo, reconstruyendo o recreando espacios perdidos y añadiendo datos históricos que faciliten la interpretación del sitio (Badilla y Sandoval, 2015) (Leiva y Moreno, 2015).

\subsection{Proyecto de investigación Amón_RA}

El proyecto 'Amón_RA. Implementación de la realidad aumentada como herramienta para la puesta en valor y difusión del PUH de barrio Amón' constituye un esfuerzo interdisciplinar e interuniversitario por desarrollar realidad aumentada al servicio de la puesta en valor de la ciudad y los recursos patrimoniales, a través del concepto del PUH. La investigación, desarrollada desde el año 2017, es financiada por la Vicerrectoría de Investigación y Extensión del Tecnológico de Costa Rica (TEC), y llevada a cabo por las escuelas de Arquitectura y Urbanismo, Computación y Diseño Industrial del mismo centro de enseñanza; además, cuenta con la colaboración del Departamento de Geografía de la Universidad Autónoma de Madrid, la Municipalidad de San José y el Centro de Investigación y Conservación del Patrimonio Cultural del Ministerio de Cultura y Juventud.

Este proyecto busca brindar a la población (residente y visitante de barrio Amón) un instrumento que permita enriquecer la experiencia de visitar uno de los espacios más emblemáticos de la ciudad de San José, donde aún se conservan un buen número de edificaciones patrimoniales y su trazado urbano corresponde al primer ensanche de la ciudad.

Este proyecto se ha nutrido del esfuerzo investigador de profesores del TEC y la UAM, así como un equipo de estudiantes, que a lo largo de la investigación han participado activamente de las etapas de desarrollo. Asimismo, se ha contado con la colaboración de vecinos y las instituciones de barrio Amón, que gentilmente se involucraron en los procesos participativos que se han llevado a cabo para la obtención de datos de interés y validación de la información para el proyecto.

Como resultado de la investigación se espera contar con una aplicación móvil conocida como Amón_RA que incorpora realidad aumentada dentro de sus funcionalidades, además de una página web donde se encontrarán contenidos adicionales que permitirán entender barrio Amón como un PUH.

\subsection{Barrio Amón, como paisaje urbano histórico}

Hacia finales del siglo XIX, San José, Costa Rica, se caracterizaba por ser una pequeña ciudad de origen colonial que, bajo los ideales liberales de la época, empezaba a cambiar su fisonomía para convertirse en una urbe con aspiraciones europeas (Quesada, 2007). El auge económico de la época, impulsado por la exportación del café, provocó interés en el crecimiento urbano y en la importación de estilos arquitectónicos predominantes de la época.

Amón es un barrio ubicado en lo que hoy puede considerarse como el corazón de la ciudad de San José; no obstante, en sus orígenes fue el primer ensanche de la capital, ubicado en una zona que en aquellos años era entendida como 'geográficamente marginal' (Hernández e 


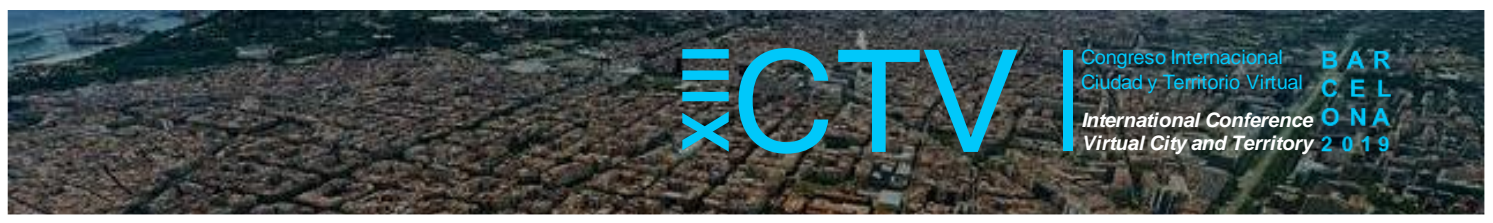

Hidalgo, 2010) debido las pronunciadas pendientes en algunos de sus sectores, su vocación cafetalera, los problemas de suciedad e inundaciones y la cercanía a los márgenes del río Torres, límite norte del cantón.

Según Quesada (2004), en 1892 se presentó un proyecto a la Municipalidad de San José que pretendía urbanizar la zona. El gestor de la urbanización fue Amón Fasileu-Duplantier, un francés radicado en Costa Rica que se dedicaba al beneficio del café; quien vio una oportunidad de crecimiento de la ciudad, ofreciendo a las familias más pudientes de la época un nuevo barrio donde asentarse. El contrato de construcción se firmó en 1894, en este se establecía que Fasileu-Duplantier realizaría la urbanización de un sector, mientras que el municipio se encargaría de la otra parte, aunque esta última, debía pagar todo el capital invertido por el promotor.

Hacia 1897 se realizó la lotificación del barrio y la dotación de servicios básicos, pero la construcción de viviendas y el poblamiento se inició hasta 1910. El primer cuarto del siglo XX dejó un barrio consolidado, con viviendas que responden a estilos arquitectónicos como el neoclásico, victoriano, neomudéjar, ecléctico, además de algunas que recordaban aún al pasado colonial. Estos nuevos estilos, no sólo generaron novedad, sino que se volvieron representativos de las clases sociales que habitaban en la zona.

Conforme pasaron los años, entre las décadas de 1950 y 1970, inició un proceso de transformación de los usos del suelo del barrio; empezaron a instalarse instituciones públicas como el Instituto Nacional de Vivienda y Urbanismo, la Escuela Técnica Nacional (cuyo edificio posteriormente fue donado al Tecnológico de Costa Rica) y el Instituto Nacional de Seguros; cuyos edificios de gran altura vinieron a romper la homogeneidad de la escala de Amón. Más adelante, hacia la década de los 80 empezaron a abrirse los primeros hoteles en el barrio, los cuales, aprovechando el atractivo de la zona, incluyeron al turismo en la dinámica urbana y económica.

Estas transformaciones morfológicas y funcionales, sumadas a cambios generacionales, han provocado paulatinamente el desinterés de algunos propietarios en residir en el barrio. Si a esto se añade la proliferación de negocios que promueven el turismo sexual, así como la especulación inmobiliaria, y otras problemáticas urbanas, puede entenderse el fenómeno de despoblamiento y terciarización que vive barrio Amón.

A pesar de ello, Amón aún conserva un significativo número de residentes, que han aprendido a convivir con la mixtura de usos y la dinámica actual del vecindario; resalta la organización comunal existente y el apoyo que reciben de parte de algunas instituciones culturales que se han establecido en la zona. Es importante indicar que barrio Amón actualmente alberga a varias instituciones académicas y culturales, asimismo se ha convertido en un sitio de interés para el desarrollo de emprendimientos gastronómicos y creativos, que dan un carácter único al barrio. Además, barrio Amón forma parte del Centro Histórico de San José y sus Ensanches, según la declaratoria oficial de la Municipalidad de San José (2013).

El proyecto Amón_RA decidió aplicar el concepto de PUH (UNESCO, 2011) para estudiar barrio Amón en virtud de ser un palimpsesto dentro de la ciudad de San José, donde son legibles una serie de capas arquitectónicas y urbanas ubicadas en un contexto natural marcado por una abrupta topografía y la presencia del río Torres. Asimismo, se trata de un espacio 


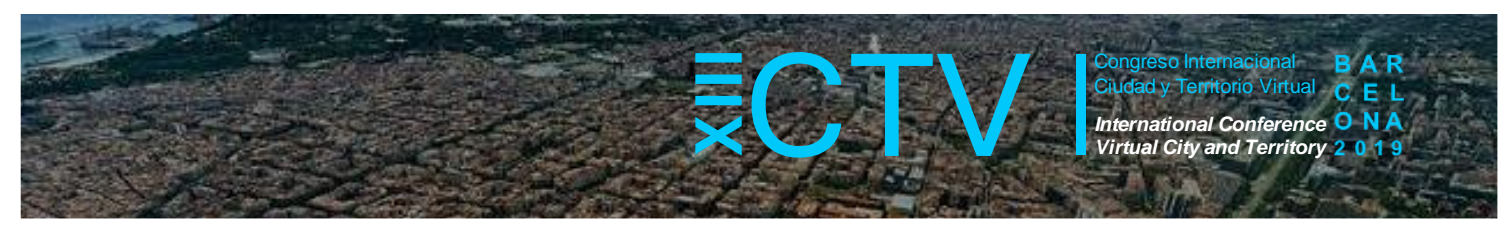

marcado por el recuerdo de hechos históricos y personajes importantes para el país, que actualmente guarda un lugar especial dentro del imaginario urbano y la memoria colectiva de los costarricenses.

Amón no es un barrio abandonado o museificado, es más bien un espacio dinámico, donde conviven pasado y novedad. Es un barrio, que a pesar de las problemáticas que lo aquejan se resiste a desaparecer como vecindario, aunque haya una apertura cada vez mayor a recibir comercios e instituciones públicas y culturales, especialmente.

Bandarin y van Oers (2012) señalan que dentro del concepto de PUH se encuentra implícito el reconocimiento de una serie de capas de significados y valores históricos de la ciudad, que han sido depositados a través del tiempo por diferentes personas bajo diversas coyunturas. Para Khalaf (2018) el PUH intenta reconectar diferentes aspectos del patrimonio: lo estático y lo dinámico, lo cultural y lo natural, lo tangible y lo intangible; esto elimina los límites que confinan al patrimonio en un mundo siempre cambiante e intenta conciliar las ideas de desarrollo y conservación.

Tomando todo esto en cuenta, el proyecto Amón_RA ha documentado los componentes del PUH de barrio Amón para presentarlos al público a través del uso de TIC, con el fin de poner en valor este sector josefino y contribuir a su dinamización. Esta aportación se centra en mostrar los resultados de la identificación de recursos del PUH del barrio, que tras un proceso de clasificación fueron traducidos a contenidos para la aplicación Amón_RA.

\section{Metodología}

El proyecto Amón_RA ha llevado a cabo una investigación desde varios frentes, por una parte, lo concerniente al desarrollo de realidad aumentada, aplicaciones móviles y creación de páginas web; y, por otra parte, se realizó el estudio del PUH de barrio Amón, lo cual ha permitido generar los contenidos necesarios para los componentes tecnológicos del proyecto; esta aportación se centra en los resultados obtenidos en este último aspecto. Para ello, la metodología aplicada en esta ponencia busca:

1. Evidenciar los recursos que han sido identificados por el proyecto, desde la perspectiva de la revalorización de este espacio como PUH y desde las oportunidades de dinamización económica y social.

2. Propiciar procesos que estimulen la atracción por la zona y que puedan vincularse a los diferentes agentes sociales.

3. Analizar el patrimonio como fuente de actividad y espacio público para el intercambio social.

El estudio del PUH se realizó a partir del análisis de una serie de componentes definidos en la Recomendación de UNESCO (2011), a saber: "topografía, geomorfología, hidrología y características naturales; el medio urbanizado, tanto histórico como contemporáneo; las infraestructuras, tanto superficiales como subterráneas; los espacios abiertos y jardines, la configuración de los usos del suelo y su organización espacial; las percepciones y relaciones visuales; y todos los demás elementos de la estructura urbana. También incluye los usos y valores sociales y culturales, los procesos económicos y los aspectos inmateriales del patrimonio en su relación con la diversidad y la identidad." (s.p.). 


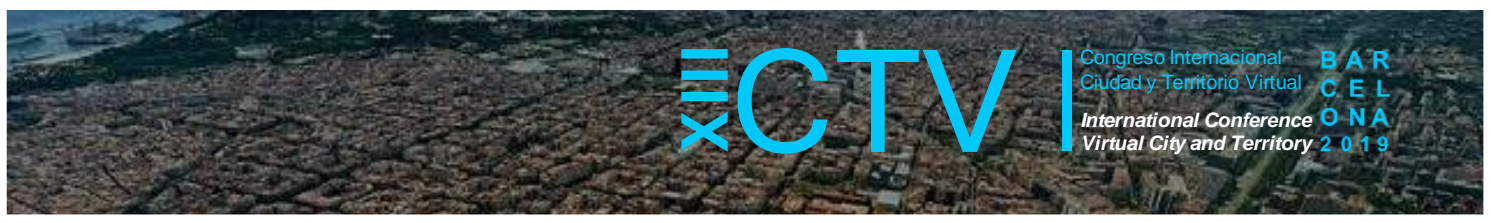

Primeramente, se realizó un estudio documental, basado en fuentes primarias (tales como archivos y fotografías históricas) y fuentes secundarias (publicaciones en libros, prensa, etc.). Esto permitió reconstruir el pasado de barrio Amón, descubriendo personajes y hechos importantes. Con la información obtenida se generó una línea del tiempo interactiva empleando la herramienta Tiki-toki con la finalidad de poder validarla y añadir nuevos datos a través de un proceso participativo posterior.

Una segunda actividad consistió de un minucioso trabajo de campo que permitió documentar fotográficamente el barrio y avanzar en la identificación, desde el punto de vista técnico, de los diferentes aspectos que conforman el PUH. Ambas actividades permitieron a los investigadores un acercamiento preliminar al área de estudio.

Siguiendo la Recomendación de UNESCO (2011) en cuanto a la importancia de la participación social para la determinación de los valores de la zona urbana y la necesidad de vincular a las personas en la salvaguarda del patrimonio y promoción del desarrollo sostenible, el proyecto realizó una serie de actividades que promovieron la participación de vecinos y usuarios de barrio Amón. Durante el II semestre de 2017 se realizaron tres talleres participativos (tabla 1) y tres jornadas de investigación vinculadas a las temáticas del proyecto.

Los dos primeros talleres participativos tuvieron como fin recopilar aspectos vivenciales, perceptuales, anecdóticos e históricos del barrio, que no se encuentran en los archivos documentales tradicionales; además de validar la información obtenida y procesada por el equipo investigador en la primera etapa del proyecto, con la visión del PUH de vecinos y usuarios de barrio Amón, a partir de su vivencia del espacio en la cotidianeidad. Durante esos talleres se lograron desarrollar dos actividades particulares cuyo objetivo era propiamente obtener información de los participantes como posibles usuarios de Amón_RA. En el tercer taller se evaluó un prototipo digital (digital prototyping) para valorar requerimientos de la aplicación desde el punto de vista de la usabilidad, a partir de la percepción de un grupo representativo de personas de diferentes sexos y edades.

Tabla 1. Síntesis de los talleres participativos

\begin{tabular}{|c|c|c|c|}
\hline $\begin{array}{l}\text { Taller / } \\
\text { fecha }\end{array}$ & $\begin{array}{l}\text { Nombre de } \\
\text { la actividad }\end{array}$ & Objetivo & Técnica utilizada \\
\hline \multirow{3}{*}{$\begin{array}{c}\text { Taller } 1 \\
(28 / 09 / 17)\end{array}$} & $\begin{array}{l}\text { Pared del } \\
\text { tiempo }\end{array}$ & $\begin{array}{l}\text { Corroborar la veracidad de los hitos históricos del } \\
\text { barrio identificados en la investigación previa, así como } \\
\text { recopilar mayor información mediante el aporte de los } \\
\text { participantes en el taller. }\end{array}$ & $\begin{array}{l}\text { Línea del tiempo de } \\
\text { construcción } \\
\text { colaborativa }\end{array}$ \\
\hline & $\begin{array}{l}\text { ¿Cómo es } \\
\text { nuestro } \\
\text { barrio? }\end{array}$ & $\begin{array}{c}\text { Contrastar la información de la imagen urbana } \\
\text { identificada por los actores sociales del barrio con la } \\
\text { obtenida en la actividad "Imagínate en Amón”, } \\
\text { desarrollada durante el Festival Amón Cultural 2017, } \\
\text { como ejercicio piloto. }\end{array}$ & Cartografía social \\
\hline & $\begin{array}{l}\text { ¿Cómo te } \\
\text { imaginas } \\
\text { Amón_RA? }\end{array}$ & $\begin{array}{c}\text { Conocer los diferentes involucrados y sus motivaciones } \\
\text { con el proyecto. Identificar posibles ideas de } \\
\text { funcionalidades o contenidos que puede tener la } \\
\text { aplicación. Identificar las métricas (factores críticos de } \\
\text { éxito) para la aplicación. Identificar posibles fallas de la } \\
\text { aplicación. }\end{array}$ & $\begin{array}{l}\text { Metodología de } \\
\text { requerimientos y } \\
\text { diseño de } \\
\text { interfases }\end{array}$ \\
\hline
\end{tabular}




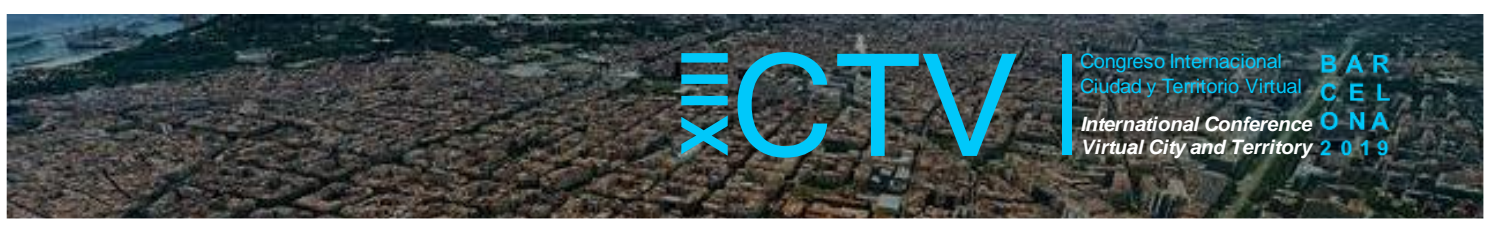

\begin{tabular}{|c|c|c|c|}
\hline \multirow{2}{*}{$\begin{array}{c}\text { Taller 2 } \\
(05 / 10 / 17)\end{array}$} & $\begin{array}{c}\text { Afiche } \\
\text { anecdótico }\end{array}$ & $\begin{array}{c}\text { Complementar la información técnica y documental de } \\
\text { cada uno de los afiches correspondientes a las } \\
\text { edificaciones patrimoniales del barrio, con información } \\
\text { anecdótica, desconocida o con aquellos sucesos no } \\
\text { registrados pero que hacen parte valiosa del acervo } \\
\text { vivencial de sus habitantes. }\end{array}$ & $\begin{array}{c}\text { Pizarra } \\
\text { colaborativa e } \\
\text { interactiva, a partir } \\
\text { de la narración de } \\
\text { los participantes }\end{array}$ \\
\cline { 2 - 5 } & Card Sorting & $\begin{array}{c}\text { Generar una categorización de contenidos a partir de } \\
\text { las relaciones de información que realizan una muestra } \\
\text { de posibles usuarios. }\end{array}$ & $\begin{array}{c}\text { Categorización de } \\
\text { contenidos }\end{array}$ \\
\cline { 2 - 5 } & $\begin{array}{c}\text { Fotos e } \\
\text { identidad }\end{array}$ & $\begin{array}{c}\text { Recopilar información asociada a la vida doméstica de } \\
\text { quienes habitan o habitaron barrio Amón a partir de } \\
\text { fotos antiguas. }\end{array}$ & $\begin{array}{c}\text { Fotografía y } \\
\text { memorias }\end{array}$ \\
\hline $\begin{array}{c}\text { Taller 3 } \\
(07 / 12 / 17)\end{array}$ & $\begin{array}{c}\text { Digital } \\
\text { Prototyping }\end{array}$ & Realizar pruebas de contenido y funcionalidad. & $\begin{array}{c}\text { Maqueta virtual } \\
\text { (wireframe) }\end{array}$ \\
\hline
\end{tabular}

Fuente: Elaboración propia.

En dichos talleres participativos se contó con la asistencia de un total de 48 personas, provenientes de diversos sectores representativos del barrio, entre ellos vecinos, miembros de las organizaciones vecinales, representantes de instituciones públicas y culturales, estudiantes y profesores del TEC, así como empresarios. Respecto a las jornadas de investigación se contó con la participación de especialistas que presentaron 12 ponencias en temas vinculados al proyecto, desde la perspectiva del PUH y del uso de TIC.

Tras la validación y contraste de información con los agentes sociales, se procedió a la identificación de recursos y clasificación en temáticas que permitieron generar un orden de contenidos para la aplicación móvil. Los recursos identificados fueron clasificados en dos grandes grupos, en primera instancia, en función de la oportunidad que ofrecen para dar a conocer los valores patrimoniales y paisajísticos del barrio, favoreciendo la revalorización de este espacio como PUH; en segundo lugar, en función del potencial que diversas actividades ofrecen para la dinamización económica y social de Amón.

La traducción de información a contenidos de la aplicación móvil fue un proceso que requirió de la elaboración de recursos multimedia (texto, audios, videos, modelos 3D, fotografías $360^{\circ}$, mapas, geolocalización de información) referente tanto a aspectos tangibles como intangibles del barrio. En muchos casos, este proceso implicó llevar a cabo un acercamiento más detallado a algunos de los elementos, por ello se realizaron entrevistas a propietarios de algunas edificaciones, levantamientos arquitectónicos, toma de fotografías, geolocalización mediante GPS y sistematización mediante una matriz de la oferta urbana del barrio.

Una vez finalizada la clasificación de contenidos con el aporte de los actores sociales, el equipo investigador procedió a la elaboración de la Arquitectura de Información Beta y el Wireframe como insumos guía para el proceso de desarrollo de la aplicación móvil y página web.

\section{Resultados}

Con base en la metodología señalada, esta ponencia ha obtenido diversos resultados que evidencian el potencial de los recursos para la revalorización de este espacio como PUH y como oportunidad de dinamización económica y social. Los recursos tangibles y algunos intangibles, que han podido asociarse a espacios físicos, se han geolocalizado y se presentan a través de mapas, con información actualizada al 9 de agosto de 2019. Con respecto a los 


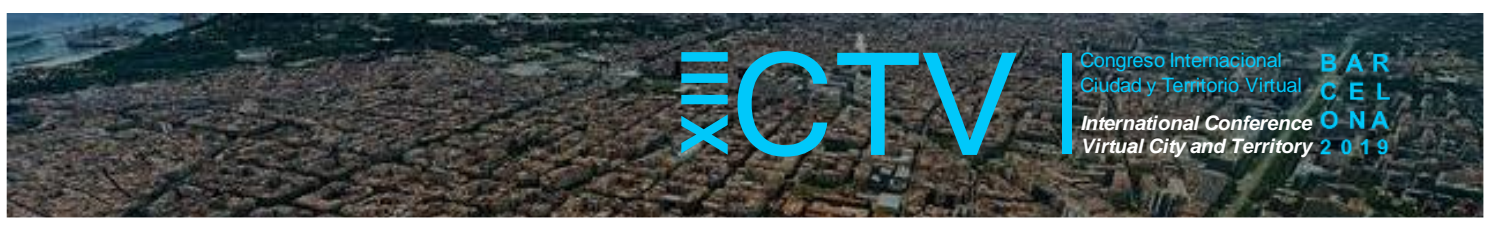

recursos con potencial para la revalorización de barrio Amón como PUH se lograron ubicar 23 edificaciones de interés arquitectónico, nueve de las cuales cuentan con declaratoria de Patrimonio Histórico-Arquitectónico (figura legal de protección). Además, se logró identificar siete espacios a los que se les denominó 'Pasado perdido', los que responden a edificaciones desaparecidas pero que aún se mantienen en la memoria colectiva, al igual que 19 espacios en los cuales se establecieron 'Secretos', entendidos como aspectos poco conocidos de los inmuebles, pero interesantes de difundir. Finalmente, dentro de esta categoría, se localizaron tres elementos naturales de importancia para el barrio (figuras 1 y 2 ).

\section{Figura 1. Recursos para revalorización del PUH de barrio Amón}

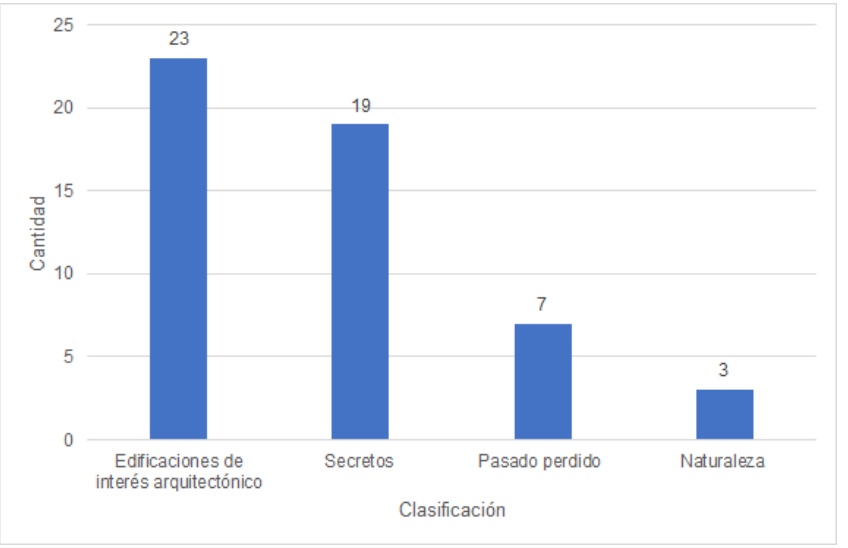

Fuente: Elaboración propia.

Figura 2. Localización de recursos para la revalorización del PUH de barrio Amón

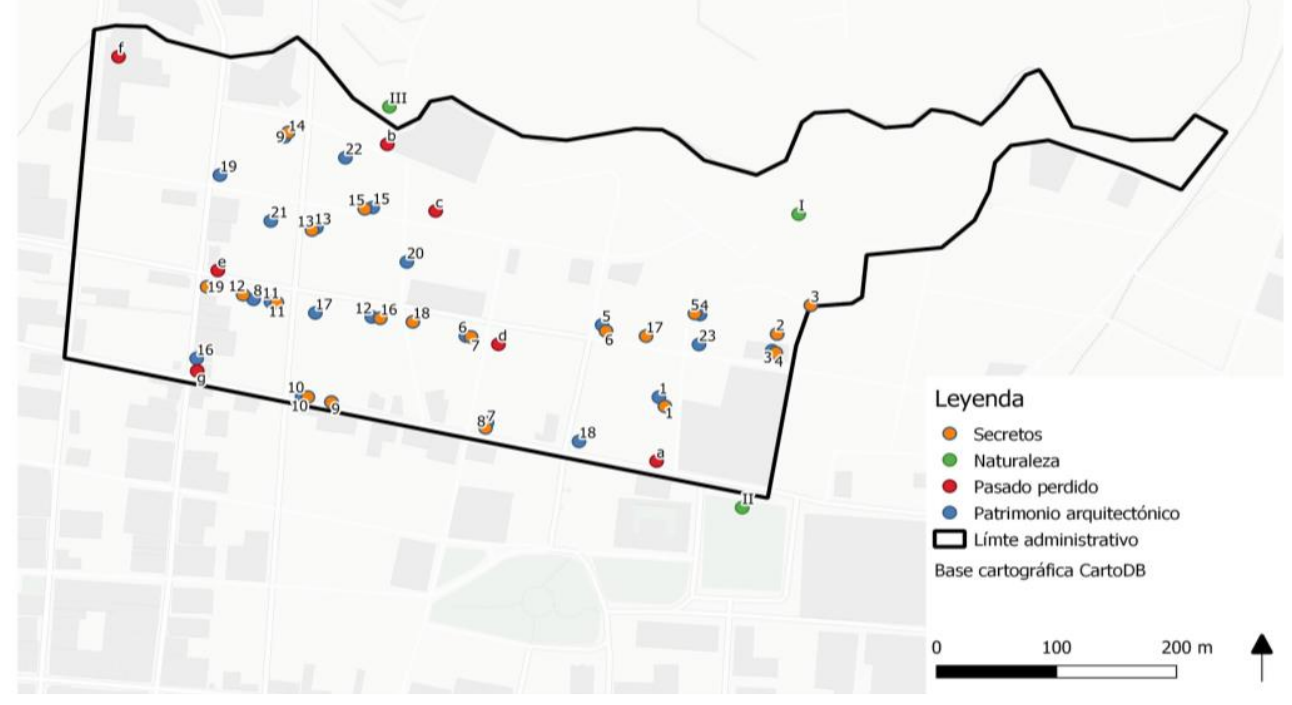

Fuente: Elaboración propia. Simbología: Secretos (1. Casa González Feo; 2.Casa Brenes Méndez; 3. Antigua entrada Zoológico Simón Bolívar; 4. Centro Costarricense de Producción Cinematográfica; 5. Casa Calvo Peña; 6. Casa Saborío González (Casa Verde); 7. Casa Coto Cubero; 8. Alianza Cultural Franco Costarricense; 9. Casa Quesada Avendaño; 10. Casa Elías Pagés Elías; 11. Antigua Residencia de Joaquín Tinoco Granados; 12. Casa Huete Quirós; 13. Residencia Cipriano Herrero del Peral; 14. Castillo del Moro; 15. Casa Serrano Bonilla; 16. Casa Mariano Álvarez Melgar; 17. Antigua Residencia de don Julio Acosta García; 18. Antigua Casa de las Ich; 19. Antiguo Local de "Curruzo" El Zapatero) / Naturaleza (I. Parque Zoológico y Jardín Botánico Nacional Simón Bolívar; II. Parque España; III. Río Torres) / Pasado perdido (a. Antiguo Hotel Rey Amón; b. Antiguo Beneficio Tournón; c. Antigua Casa Jaime 


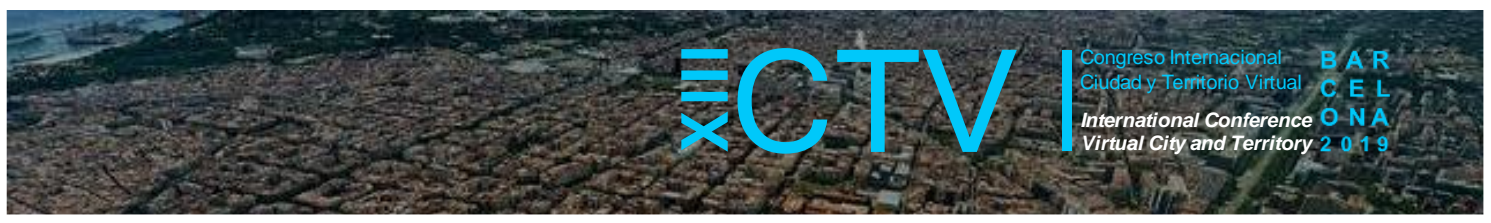

Bennett; d. Antigua Casa Keith Alvarado; e. Antigua Casa de Juanita Mora; f. Antigua Cervecería Traube; g. Antiguo Bar Limón) / Patrimonio arquitectónico (1. Casa González Feo; 2. Casa Brenes Méndez; 3. Centro Costarricense de Producción Cinematográfica; 4. Casa Calvo Peña; 5. Casa Saborío González (Casa Verde); 6. Casa Coto Cubero; 7. Alianza Cultural Franco Costarricense; 8. Casa Huete Quirós; 9. Castillo del Moro; 10. Casa Elías Pagés Elías; 11. Casa José Joaquín Tinoco Granados (Casa Familia Lehmann); 12. Casa Mariano Álvarez Melgar; 13. Casa Cipriano Herrero del Peral; 14. Casa Quesada Avendaño; 15. Casa del Barrio Amón (Casa Serrano Bonilla); 16. Casa Utilio Ulate Blanco; 17. Casa Alejo Aguilar Bolandi; 18. Casa Museo 707 (Casa Mireya Gurdián Agüero); 19. Casa Familia Madriz; 20. Casa 936 (Casa Familia Castro Odio); 21. Casa Familia Ollé; 22. Casa Obregón Loría; 23. Antiguo Hotel Hemingway Inn).

Como recursos con potencial de dinamización económica y social, destaca la presencia de locales dedicados a la gastronomía, hospedaje, cultura y arte e institucional, para un total de 48 sitios, los cuales fueron denominados para este proyecto como 'Oferta Urbana' (figuras 3 y 4). Estos destacan como atractores de actividad diurna y nocturna, generando flujos continuos a nivel de visitación y actividad económica. Estos recursos fueron localizados y se desarrolló una matriz con información detallada para su ubicación, contacto y vinculación en redes sociales; información que estará disponible en la aplicación móvil y página web para el servicio de los usuarios del barrio.

\section{Figura 3. Recursos para la dinamización económica y social de barrio Amón}

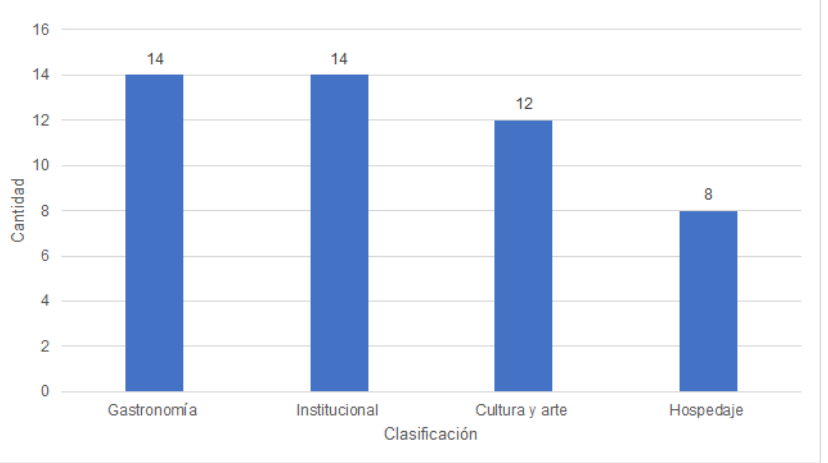

Fuente: Elaboración propia.

Figura 4. Localización de Recursos para la dinamización económica y social de barrio Amón

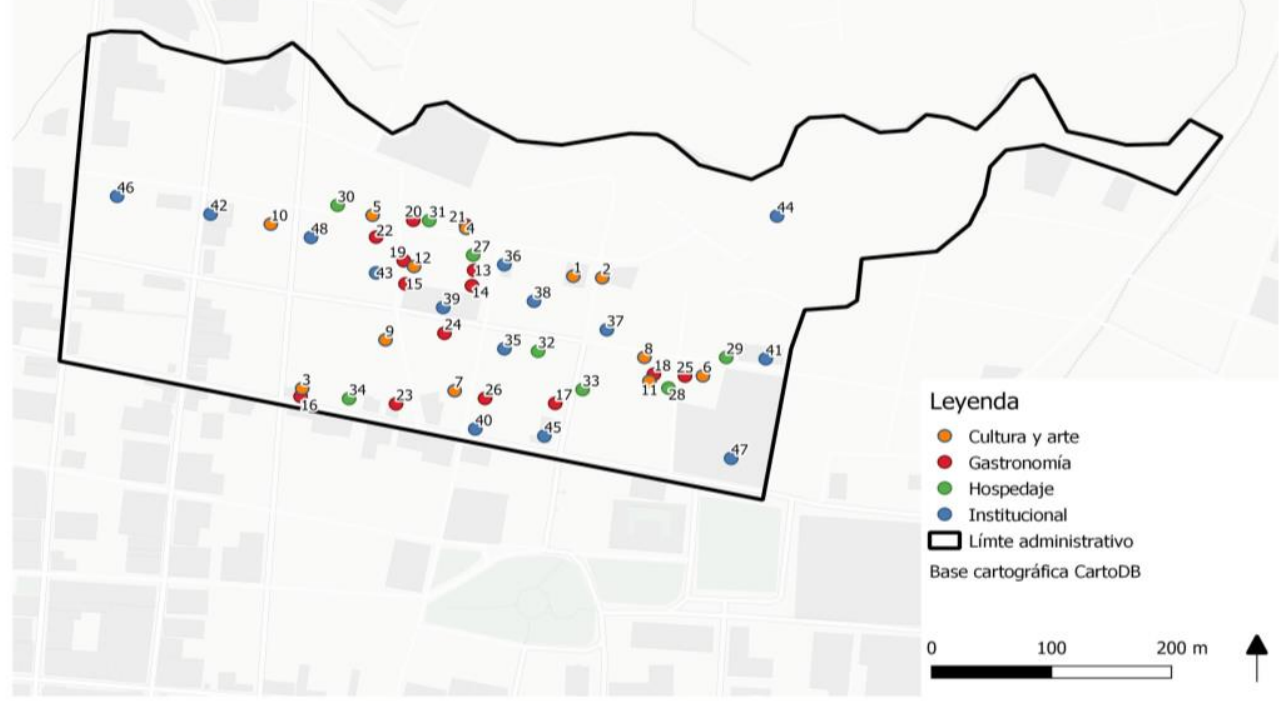




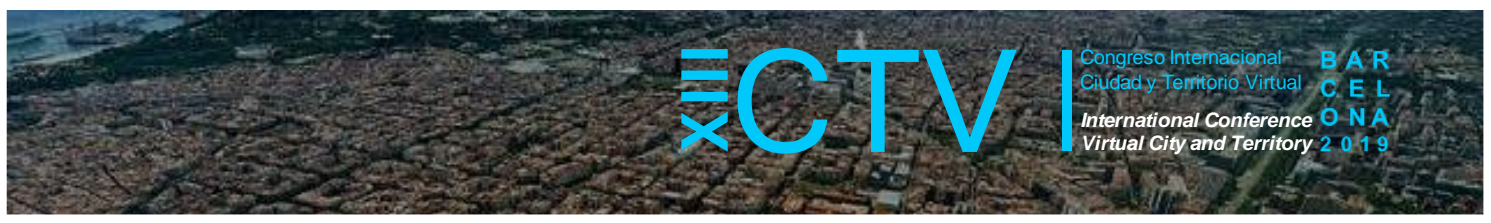

Fuente: Elaboración propia. Simbología: Cultura y arte (1. TEOR/éTica; 2. Lado V. Centro de estudio y documentación; 3. Libros Duluoz; 4. Galería Talentum (Antigua Casa Familia Doryan); 5. Casa del Barrio Amón (Casa Serrano Bonilla); 6. Camanance. Taller y Tienda; 7. Matisse Cine Espacio-Temporal; 8. Murales de Cuentos de Concherías; 9 . Triángulo Showroom Creativo; 10. Amon Solar / El Sótano; 11. Boutique Annemarie Gift \& Shop; 12. Insólita) / Gastronomía (13. Alma de Amón; 14. Soda Yasmin; 15. De acá; 16. Café Rojo; 17. Café Europa; 18. Café Amón; 19. Cafenauta; 20. Restaurante II Gattopardo; 21. Tournant Restaurante y Café; 22. Restaurante Silvestre (Antigua Casa Peralta Zeller); 23. Delicias Del Perú; 24. Criollita Amón. Restaurante y Café; 25. PANÍ-VORO; 26. Le Café) / Hospedaje (27. Hotel Dunn Inn; 28. Hotel Don Carlos; 29. Hotel Castillo; 30. Hotel Inca Real San José; 31. Hotel y Casino Taormina San José; 32. Hotel Kekoldi; 33. Hostel Van Gogh; 34. Hostel Pangea) / Institucional (35. Escuela de Arquitectura y Urbanismo - TEC; 36. Casa Cultural Amón - TEC; 37. Escuela de Computación - Administración de Empresas - TEC; 38. Tecnológico de Costa Rica (TEC); 39. Instituto Nacional de Vivienda y Urbanismo (INVU); 40. Alianza Cultural Franco Costarricense; 41. Centro Costarricense de Producción Cinematográfica; 42. Dirección Regional de Educación de San José (MEP); 43. Casa Santa Margarita; 44. Fundación Pro Zoológicos (FUNDAZOO); 45. Instituto Mixto de Ayuda Social (IMAS); 46. Cooperativa Coopemep R.L.; 47. Instituto Nacional de Seguros (INS); 48. Fondo de Desarrollo Social y Asignaciones Familiares (FODESAF)).

Todos los recursos anteriormente descritos se han documentado a través de diferentes medios y se han traducido a contenidos de la aplicación móvil según la Arquitectura de Información Beta desarrollada para el proyecto (figura 5) y la página web de Amón_RA. A la fecha se ha logrado obtener: siete modelos 3D de edificaciones con valor patrimonial (figura 6), un glosario ilustrado con 39 términos arquitectónicos asociados a 13 inmuebles sobresalientes del barrio, una línea del tiempo interactiva, fotografías aéreas del barrio obtenidas mediante el uso de un dron, un mapa temático e interactivo donde se muestran todos los recursos y la aplicación de realidad aumentada a través de la superposición fotográfica en 32 sitios del barrio (figura 7).

Figura 5. Arquitectura de Información Beta

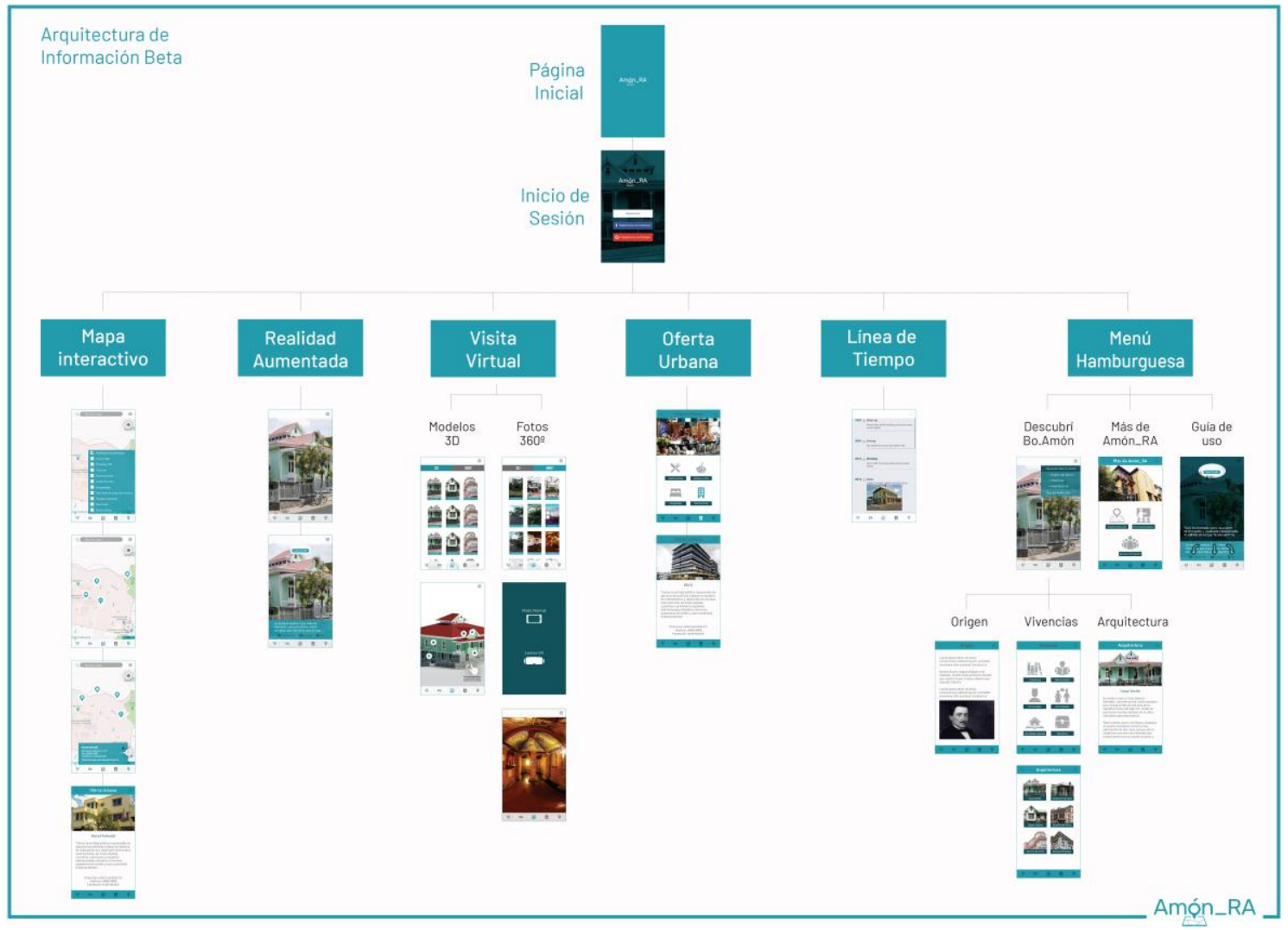

Fuente: Proyecto Amón_RA. 


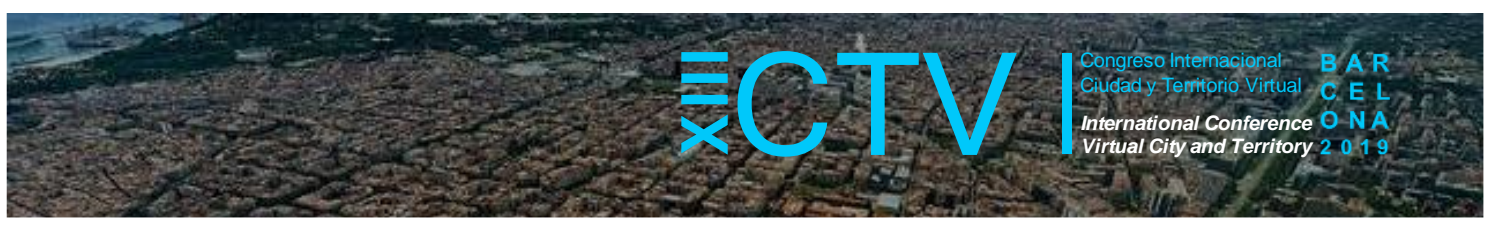

Figura 6. Modelo 3D de la Casa Saborío González (Casa Verde)

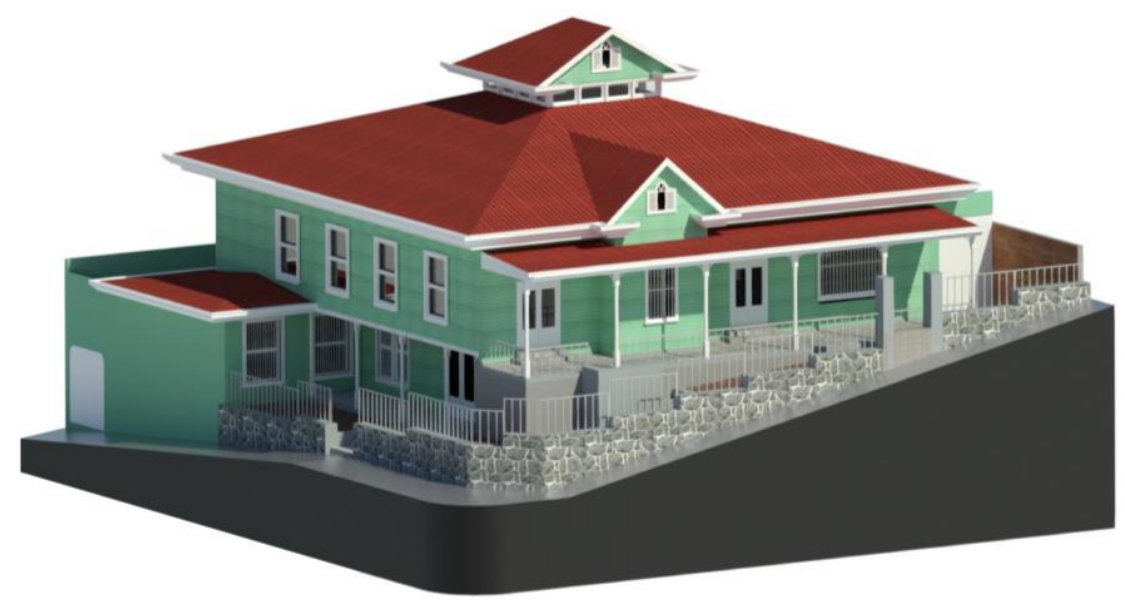

Fuente: Proyecto Amón_RA.

Complementariamente, se utilizan recursos textuales y fotográficos para mostrar alguna de la información obtenida en los talleres y como parte del proceso de revisión documental y bibliográfica del barrio. En total se elaboraron 11 extractos de literatura referida a Amón; cinco narraciones de los propios participantes en los talleres; 22 breves biografías de personajes asociados a la historia del barrio y sus edificaciones entre los que destacan políticos, escritores, artistas, entre otros; y finalmente, tres narraciones anecdóticas sobre actividades barriales.

Figura 7. Pruebas del uso de realidad aumentada con la aplicación Amón_RA

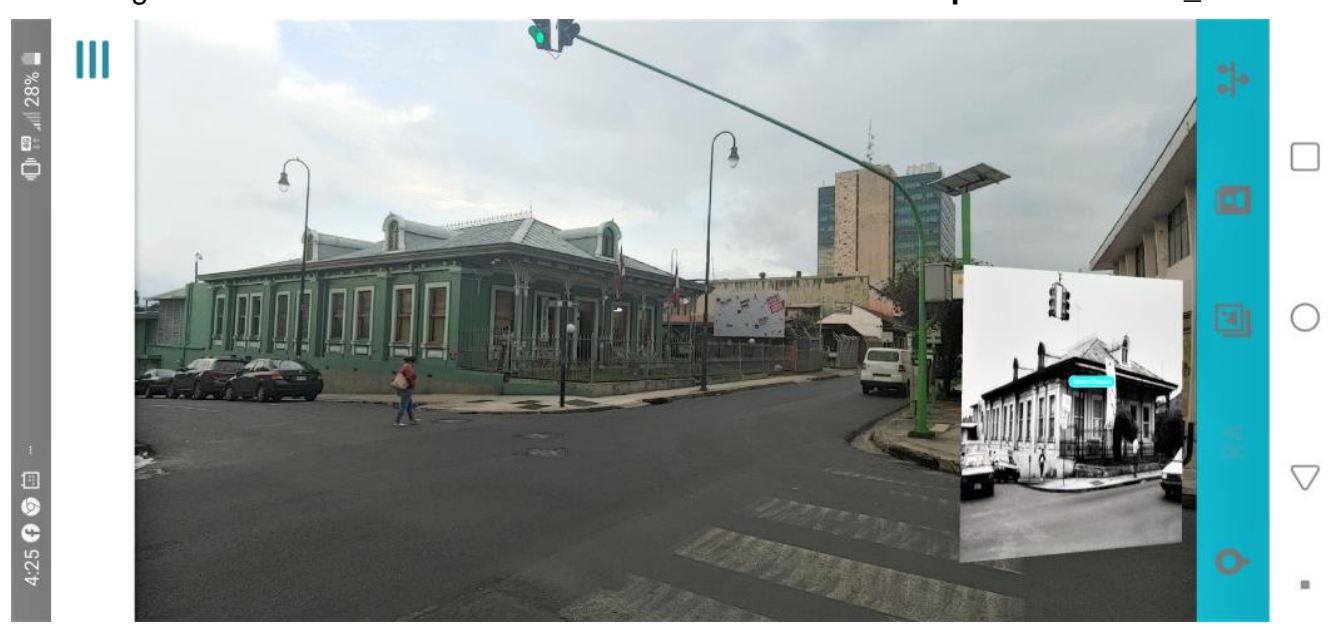

Fuente: Proyecto Amón_RA.

\section{Conclusiones}

Como principal conclusión, se evidencia que, a pesar de su despoblamiento y terciarización, Amón es un barrio josefino que cuenta con una serie de valores patrimoniales de tipo histórico, estético, simbólico, cultural y social que lo convierten en un referente de la ciudad y de los diversos procesos que han moldeado su configuración urbana. Además, cuenta con una serie de recursos y servicios con potencial para dinamizar el barrio a través de las TIC. 


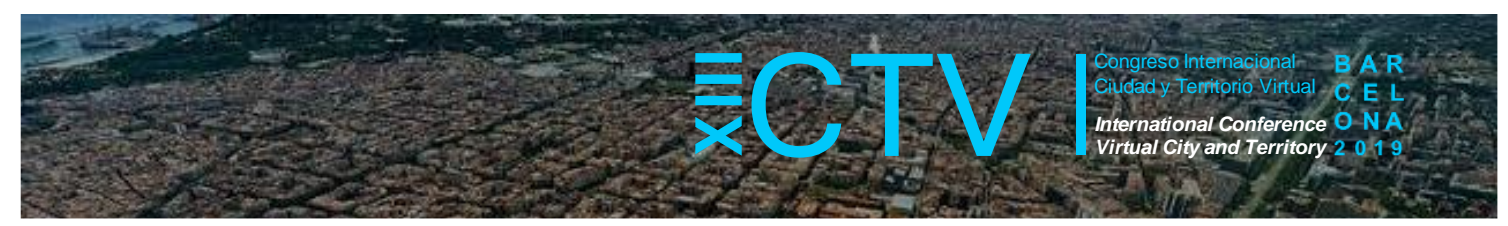

Las TIC aplicadas al patrimonio, y en específico al PUH, constituyen una oportunidad para mejorar la experiencia de los usuarios, contribuyendo a un mayor reconocimiento de los valores y potencialidades de los espacios urbanos históricos; así como al fortalecimiento de las actividades económicas y sociales.

La figura del PUH permite una comprensión más integral de la ciudad, superando otros conceptos como 'conjunto histórico' o 'centro histórico'. La participación ciudadana constituye un elemento esencial para la comprensión del PUH pues garantiza la identificación de la población con los elementos patrimoniales tangibles e intangibles, dentro de un contexto urbano estratificado y complejo.

Mediante la metodología abordada se logró la identificación de los recursos para la revalorización del PUH y dinamización social y económica del barrio. Dichos elementos no deberían ser analizados de forma individual, sino más bien se deben articular para la conformación de un producto que atraiga a un mayor número de visitantes y residentes a barrio Amón.

Si bien esta investigación se limita en primera instancia a la identificación de los recursos, queda en evidencia la necesidad de establecer un trabajo colaborativo y multisectorial para lograr la conservación del PUH y el aprovechamiento de las oportunidades de desarrollo que ofrece barrio Amón. Por un lado, se debería trabajar en la conservación de los recursos mediante la sensibilización de la población, como podría ser mediante el uso de TIC; pero también, a través de proyectos de intervención patrimonial en las edificaciones, preservación de la memoria histórica y la creación de una figura de protección a nivel urbanístico que resalte el PUH.

Por otra parte, los recursos identificados a nivel de dinamización económica y social, en la mayoría de los casos, son recursos aislados, lo cual, para los emprendimientos culturales y gastronómicos, disminuye sus posibilidades de permanencia al no contar con una estrategia colectiva de atracción al barrio. Si bien Amón cuenta con un nivel de articulación vecinal, es necesario fortalecer las sinergias que puedan contribuir al desarrollo económico y social de la zona, en las que participen empresarios, instituciones públicas, emprendimientos, la academia y los vecinos como actores sociales que interactúan en el barrio. El proyecto Amón_RA constituye un paso para la articulación de estos actores mediante el uso de TIC para revalorizar y dinamizar este espacio urbano.

Agradecimientos: A la Vicerrectoría de Investigación y Extensión del Instituto Tecnológico de Costa Rica por el financiamiento brindado para el desarrollo del proyecto 'Amón_RA. Implementación de la realidad aumentada como herramienta para la puesta en valor y difusión del paisaje urbano histórico de barrio Amón', del cual se desprende esta ponencia. Asimismo, agradecemos al equipo investigador y estudiantil por su aporte al proyecto.

Contribuciones de los autores: Ambos autores han desarrollado en conjunto todos los apartados de esta ponencia.

Conflicto de Intereses: Los autores declaran que no hay conflicto de intereses. 


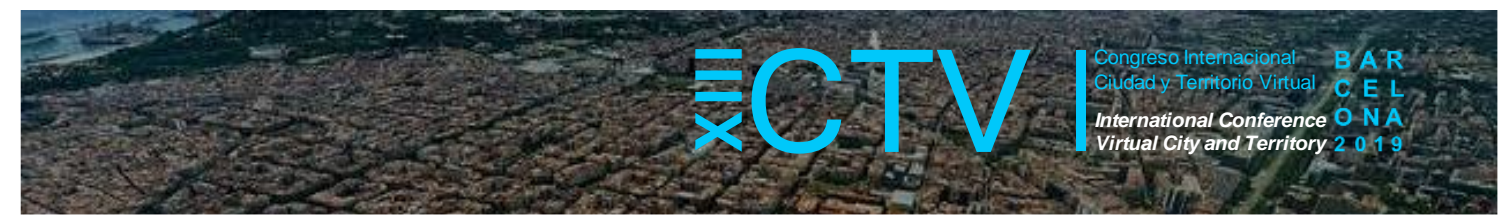

\section{Bibliografía}

Azuma, R. (1997). A Survey of Augmented Reality. In Presence: Teleoperators and Virtual Environments, 6 (4): 355-385.

Badilla, M. y Sandoval, A. (2015). Realidad aumentada como tecnología aplicada a la educación superior: Una experiencia en desarrollo. Innovaciones educativas, 17 (23): 41-50.

Bandarin, F., \& van Oers, R. (2012). The historic urban landscape. Managing heritage in an urban century. Chichester, Inglaterra: Wiley Blackwell.

Barrado-Timón, D. \& Hidalgo-Giralt, C. (2019). The Historic City, Its Transmission and Perception via Augmented Reality and Virtual Reality and the Use of the Past as a Resource for the Present: A New Era for Urban Cultural Heritage and Tourism? Sustainability, 11 (10): 2835. DOI: https://doi.org/10.3390/su11102835

Blanco-Pons, S.; Carrión-Ruiz, B.; Duong, M.; Chartrand, J.; Fai, S. \& Lerma, J. (2019). Augmented Reality Markerless Multi-Image Outdoor Tracking System for the Historical Buildings on Parliament Hill. Sustainability. 11 (16): 4268. DOI: https://doi.org/10.3390/su11164268

Fombona, J.; Pascual, M. y Madeira, M. (2012). Realidad aumentada, una evolución de las aplicaciones de los dispositivos móviles. Píxel-Bit. Revista de Medios y Educación, (41): 197210.

Ginzarly, M.; Houbart, C. \& Teller, J. (2018). The Historic Urban Landscape approach to urban management: a systematic review. International Journal of Heritage Studies, 25 (10): 999-1019. DOI: https://doi.org/10.1080/13527258.2018.1552615

Hernández, E. e Hidalgo, E. (2010). Barrio Amón, memoria y desarrollo. San José, Costa Rica: Instituto Tecnológico de Costa Rica.

Johnson, L.; Adams-Becker, S.; Gago, D.; García, E. y Martín, S. (2013). NMC perspectivas tecnológicas: educación superior en América Latina 2013-2018. Un análisis regional del informe Horizon del NMC. Austin, Estados Unidos: The New Media Consortium.

Khalaf, R. (2018). A Proposal to Apply the Historic Urban Landscape Approach to Reconstruction in the World Heritage Context. The Historic Environment: Policy \& Practice, 9 (1): 39-52. DOI: https://doi.org/10.1080/17567505.2018.1424615

Leiva, J. y Moreno, N. (2015). Tecnologías de geolocalización y realidad aumentada en contextos educativos: Experiencias y herramientas didácticas. DIM: Didáctica, Innovación y Multimedia, 11 (31). Recuperado de: https://www.raco.cat/index.php/DIM/article/viewFile/291534/380014

Naciones Unidas. (2016). Agenda 2030 y los Objetivos de Desarrollo Sostenible. Una oportunidad para América Latina y el Caribe. Santiago, Chile: Naciones Unidas. Recuperado de: http://www.sela.org/media/2262361/agenda-2030-y-los-objetivos-de-desarrollo-sostenible.pdf 


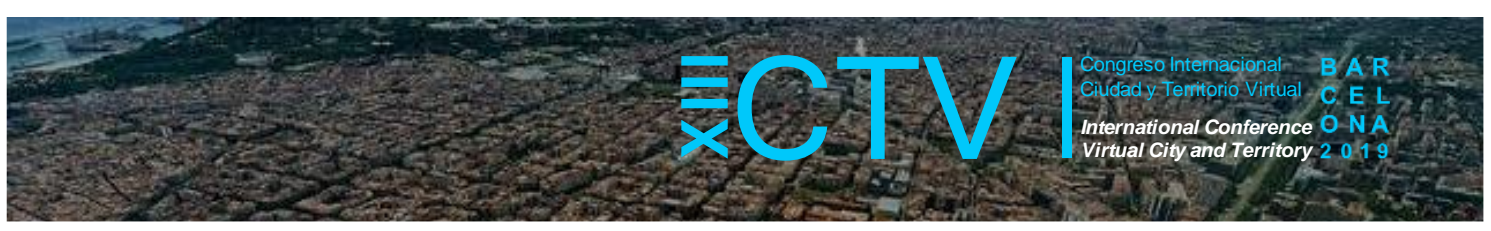

Naciones Unidas. (2017). Nueva agenda urbana - Hábitat III. Quito, Ecuador: Naciones Unidas. Recuperado de: http://habitat3.org/wp-content/uploads/NUA-Spanish.pdf

Palma, V.; Spallone, R. y Vitali, M. (2019). Augmented Turin Baroque Atria: AR experiences for enhancing cultural heritage. The International Archives of the Photogrammetry, Remote Sensing and Spatial Information Sciences, XLII-(2W9): 557-564. DOI: https://doi.org/10.5194/isprs-archives-XLII-2-W9-557-2019

Quesada, F. (2004). En el Barrio Amón: arquitectura, familia y sociabilidad del primer residencial de la elite urbana de San José, 1900-1945. San José, Costa Rica: Editorial de la Universidad de Costa Rica, Comisión Nacional de Conmemoraciones Históricas.

Quesada, F. (2007). La modernización entre cafetales: San José, Costa Rica, 1880-1930 (Tesis doctoral). Universidad de Helsinki, Helsinki.

Syahputra, M.; Andayani, U; Efendi, S.; Arisandi, D.; Abdullah, D.; Sriadhi, S.; Mouw E.; Biso, H. \& Ririhena, M. (2018). A Guidance Application for Historical Routes and Location Area with Augmented Reality. Journal of Physics, 1235 . DOI: https://doi.org/10.1088/1742$\underline{6596 / 1235 / 1 / 012077}$

Taylor, K. (2016). The Historic Urban Landscape paradigm and cities as cultural landscapes. Challenging orthodoxy in urban conservation, Landscape Research, DOI: https://doi.org/10.1080/01426397.2016.1156066

UNESCO. (2011). Recomendación sobre el paisaje urbano histórico. París, Francia: UNESCO. Recuperado de: http://portal.unesco.org/es/ev.php-URL ID=48857\&URL DO=DO TOPIC\&UR L SECTION=201.html

UNESCO. (2013). Nueva vida para las ciudades históricas. El planteamiento de los paisajes urbanos Históricos. París, Francia: UNESCO. Recuperado de: https://unesdoc.unesco.org/ark:/48223/pf0000220957 spa 